\title{
JURISPRUDENCIA CONSTITUCIONAL EN MATERIA DE PROTECCIÓN DEL MEDIO AMBIENTE (SEGUNDO SEMESTRE 2016)
}

\author{
JORDI JARIA I MANZANO \\ Profesor Serra Húnter de Derecho constitucional y ambiental \\ Universitat Rovira i Virgili
}

Sumario: 1. Atmósfera enrarecida, o cuando la contaminación del aire deja de vincularse a la protección del medio ambiente. 2. El impuesto nuclear catalán. 3. Unidad de mercado y protección del medio ambiente en el ámbito de los equipamientos comerciales. 4. La gestión de permisos y concesiones en relación con el almacenamiento geológico de dióxido de carbono. 5. Auditoría ambiental y distribución de competencias.

El período cubierto por la crónica viene marcado por la continuación de algunos de los contenciosos más significativos de los tiempos recientes, en relación con la conflictividad constitucional sobre la protección del medio ambiente. Así, el Tribunal Constitucional ha dictado la Sentencia 57/2016, de 17 de marzo (BOE, núm. 97, de 22 de abril de 2016), recaída con motivo del recurso de inconstitucionalidad interpuesto por el Gobierno de Canarias en relación con diversos preceptos de la mencionada Ley 2/2013, de protección y uso sostenible del litoral y de modificación de la Ley 22/1988, de 28 de julio, de Costas; así como la Sentencia 100/2016, de 25 de mayo (BOE, núm. 159, de 2 de julio de 2016), en relación con el recurso de inconstitucionalidad interpuesto por el Consejo de Gobierno del Principado de Asturias en relación con la misma Ley. En ellas se reitera lo ya comentado en relación con las Sentencias 233/2015, de 5 de noviembre; 6/2016, de 21 de enero; y 28/2016, de 18 de febrero.

Por otra parte, también ha dictado la Sentencia 60/2016, de 17 de marzo (BOE núm. 97, de 22 de abril de 2016), y la Sentencia 72/2016, de 14 de abril (BOE núm. 122, de 20 de mayo de 2016), que, por su parte, se refieren a lo ya resuelto en la Sentencia 32/2016, de 18 de febrero, ya comentada en la crónica anterior. Por lo demás, cabe avanzar que, en la línea que ha ido sosteniendo y profundizando en los últimos años, las resoluciones comentadas en esta crónica, la mayoría de las cuales relativas a contenciosos entre las instituciones centrales del Estado y las catalanas, insisten en la erosión de las competencias autonómicas en relación con la protección del medio ambiente, de modo 
que se va definiendo un panorama en el que la involución autonómica va pareja a la regresión ambiental.

Quizá, en esta ocasión, dicha evolución jurisprudencial queda reflejada de modo particularmente nítido, cuando, por lo demás se concentra en el territorio donde la crisis del modelo autonómico, de acuerdo con la concepción que ha ido definiendo el legislador estatal y avalando el Tribunal Constitucional, se ha puesto de manifiesto de manera más clara en los últimos años. Ello no obsta para que, en algún caso, el Tribunal Constitucional haya encontrado el modo de preservar el ámbito de la ejecución autonómica relación con la protección del medio ambiente, posición que debería inspirarle en el futuro a la hora de reconducir una línea jurisprudencial mayoritariamente tendente al desapoderamiento de las comunidades autónomas en este ámbito y, de modo casi paralelo, a la aceptación de una virtualidad estrictamente retórica en relación con el art. 45 CE. En general, sin embargo, la evolución de la jurisprudencia constitucional en relación con el Estado autonómico y, en particular, con su incidencia en la protección del medio ambiente es ya muy preocupante.

\section{Atmósfera enrarecida: cuestiones competenciales en relación con la contaminación del aire}

Es sabido que las relaciones entre la Generalitat y las instituciones centrales del Estado no pasan su mejor momento. Asimismo, es también notorio el papel que está jugando el Tribunal Constitucional en el conflicto que viene sosteniéndose desde la STC 31/2010, de 28 de junio. Los contenciosos se han multiplicado en los últimos tiempos, en el marco las medidas impulsadas por la mayoría en el Parlament de Catalunya desde las elecciones del 27 de septiembre de 2015 en relación con el ejercicio del derecho a decidir. Numerosos pronunciamientos del Tribunal Constitucional ha ido jalonando el progresivo deterioro de las relaciones entre ambas instituciones hasta crear una atmósfera enrarecida que epitomizan las decisiones adoptadas por el Juez de la Constitución en relación con una regulación relativa a la calidad del aire, sobre la que se ha pronunciado en el período considerado en la presente crónica.

Se trata de la Sentencia 53/2016, de 17 de marzo (BOE, núm. 97, de 22 de abril de 2016), en la que el Tribunal Constitucional se pronuncia en relación con el conflicto positivo de competencia núm. 2900-2011, promovido por el Gobierno de la Generalitat de Cataluña, 
frente a diversos preceptos del Real Decreto 102/2011, de 28 de enero, relativo a la mejora de la calidad del aire, y concretamente contra el último párrafo del art. 3.1 y los arts. 3.3.e), $8,9.2,12$, y 24.4 .

El conflicto se fundamenta en la apreciación por parte del Gobierno de la Generalitat de que el último párrafo del art. 3.1 y los arts. 8, 9.2, y 12 del Real Decreto vulneran el orden competencial vigente, al establecer un sistema de control y garantía de calidad del aire por el que se reserva al Estado el ejercicio de funciones estrictamente ejecutivas. Por otra parte, el Gobierno catalán considera, asimismo que los arts. 3.3.e), y 24.4 del Real Decreto 102/2011 atribuyen al Estado, facultades incondicionadas de coordinación, sin que haya título competencial habilitante y en contradicción con lo dispuesto en el art. 115 EAC. El Abogado del Estado, por su parte, considera que los títulos competenciales referidos en la disposición final segunda de la norma controvertida, esto es los apartados 16 y 23 del art. 149.1 CE, son títulos habilitantes suficientes para su intervención.

Formulado el conflicto en los términos consignados, el Tribunal Constitucional resuelve en relación con los diferentes aspectos controvertidos del Real Decreto 102/2011. En relación con el primer bloque de preceptos controvertidos, debe señalarse que, como apunta el propio Tribunal Constitucional”, "el art. 3 del Real Decreto al Estado de la implantación de puntos de muestreo para hacer concretas mediciones de diferentes contaminantes. Este precepto establece, en efecto, que la Agencia Estatal de Meteorología realizará las mediciones indicativas de las partículas finas, los metales pesados e hidrocarburos aromáticos policíclicos y las mediciones de amoníaco en estaciones rurales de fondo y los arts. 8, 9 y 12 disponen que el Ministerio de Medio Ambiente y Medio Rural y Marino, en colaboración con las Comunidades Autónomas, establezca puntos de muestreo para mediciones indicativas rurales de fondo en relación con estas sustancias" (FJ 4).

La realización de las mediciones y el establecimiento de los puntos de muestreo parece algo de carácter nítidamente ejecutivo. Sin embargo, el Tribunal Constitucional decide desvincular la medición de la composición química del aire de la competencia en materia de protección del medio ambiente. Así, según el Juez de la Constitución,

A partir de las mediciones realizadas y de los valores así obtenidos, se inicia un proceso de análisis y de elaboración de conclusiones que sirven de presupuesto para tomas de decisión posteriores sobre los niveles y umbrales que aparecen definidos 
en el art. 2 del Real Decreto 102/2011, en función de los diferentes objetivos para los que aquellas mediciones iniciales han servido de presupuesto, permitiendo de ese modo la realización de variadas iniciativas que tiendan a satisfacer diferentes objetivos, no tanto ya en materia medioambiental, cuanto también en otras distintas, que se citan en el último párrafo del art. 1 del propio Real Decreto 102/2011 (preservación de la salud o de otros bienes o intereses generales que no se especifican en el precepto, pero que se exponen con una fórmula abstracta, que puede abarcar una variedad de fines: protección civil, seguridad del tráfico aéreo, etc.).

Por tanto, el Real Decreto 102/2011 establece un régimen jurídico que tiene un alcance mucho más ambicioso que el de la exclusiva protección medioambiental. Cierto es que su art. 1 incluye como uno de sus objetivos el citado de la protección del medioambiente, pero abarca otros de diferente naturaleza. De modo expreso, el último párrafo de aquel precepto alude, no solamente al precitado, sino también a la salud humana y a otros bienes e intereses generales, sin precisa cita y a título meramente enunciativo, pero que reflejan el carácter multidisciplinar de los objetivos que pretende alcanzar esta norma [FJ 4].

Parece claro que, con el criterio del Tribunal Constitucional expresado en las líneas precedentes, es posible para el Estado excluir el título competencial en materia de protección de medio ambiente mediante la referencia genérica a cualquier finalidad más allá de la estricta protección del medio ambiente, adquiriendo con ello competencias ejecutivas directamente relacionadas con el entorno, pero que se separan del título competencial correspondiente mediante un recurso genérico a una orientación finalista, abstractamente amplia y omnicomprensiva. A partir de aquí, entra a jugar la competencia estatal del art. 149.1.20 CE, de modo que el Tribunal no tiene embarazo en considerar que el título competencial relativo al servicio meteorológico ampara aquí la acción del Estado. Que el Decreto controvertido se refiera a la mejora de la calidad del aire parece ser indiferente al Alto Tribunal, ante el "alcance mucho más ambicioso que el de la exclusiva protección medioambiental" que atribuye al Decreto. En cuanto a las facultades de coordinación, recogidas en los arts. 3.3.e), y 24.4 del Real Decreto, son, asimismo, consideradas legítimas por el Tribunal Constitucional, a pesar de que, como es sabido, el art. 149.1.23 CE no las contempla.

La decisión del Tribunal, como no podía ser de otro modo, convalida la intervención estatal en este ámbito, de modo que, para no variar, se continúa avanzando en la involución autonómica y el desapoderamiento de las comunidades autónomas, a través 
de una interpretación del Bloque de la Constitucionalidad suficientemente plástica y creativa como para permitir la ampliación del margen de maniobra estatal. La exclusión de la protección del medio ambiente como título competencial empieza a ser ya un clásico en esta jurisprudencia recentralizadora del Tribunal Constitucional, que empieza con la ya clásica STC 13/1998, de 22 de enero. De hecho, si el Alto Tribunal ya fue capaz de negar que la evaluación de impacto ambiental no se integraba en el título competencial de protección del medio ambiente, no debe ser sorprendente que la ejecución en materia de contaminación atmosférica tampoco lo sea.

Como hemos dicho reiteradamente a lo largo de las crónicas anteriores, en cualquier caso, la opción del Juez de la Constitución da lugar no solo a un desapoderamiento de las comunidades autónomas, sino también a una desprotección del medio ambiente, como se ha tenido ocasión de ver en la jurisprudencia reciente sobre la fractura hidráulica. Sin embargo, es cierto que el Tribunal utiliza la protección del medio ambiente como argumento cuando, milagrosamente, tiene la virtud de ampliar las facultades de intervención del Estado, como sucede con las funciones de coordinación contempladas por el Real Decreto 102/2011.

La preocupación en relación con la involución autonómica y sus efectos sobre la protección del medio ambiente es compartida por algunos magistrados del Tribunal Constitucional. En el caso que nos ocupa, por ejemplo, ello se pone de manifiesto con la existencia de dos votos particulares. El primero de ellos, formulado por los magistrados, Adela Asua Batarrita y Fernando Valdés Dal-Ré, defiende un punto de vista bastante similar en relación con el encuadramiento competencial de la cuestión al que he mantenido en las líneas precedentes. Lamentablemente, la sorpresa del jurista ambientalista, a la que el citado voto particular se refiere, difícilmente puede darse ya, teniendo en cuenta los precedentes del Tribunal. Sin embargo, la línea argumental del voto particular permite definir con claridad la inadecuación en la asignación de títulos competenciales que hace el Tribunal, así como los peligros que implica, tanto desde el punto de vista del Estado de las Autonomías, como desde el punto de vista de la protección del medio ambiente.

Puede concluirse, con unas palabras formuladas en el otro voto particular formulado en relación con la opinión mayoritaria del Tribunal, el que plantea el magistrado Juan Antonio Xiol Ríos: “el encuadramiento competencial que defiende la opinión mayoritaria en que se funda la sentencia no ha sido sometido a contradicción y es inadecuado con 
arreglo a una interpretación gramatical y sistemática de la Constitución y al tratamiento que los consensos sociales trabajosamente logrados imponen sobre el medio ambiente". Como coda, podría apuntarse que las decisiones del Tribunal Constitucional no son ajenas a la atmósfera enrarecida a la que nos hemos referido al inicio de este epígrafe. Por ello, empieza a ser necesaria una reflexión sobre el papel del Tribunal Constitucional en el Estado autonómico y, en particular, en relación con la cuestión catalana, así como el peligro de legitimación de la regresión en materia ambiental que entrañan muchas de sus recientes decisiones competenciales en este ámbito.

\section{El impuesto nuclear catalán}

Continuando con los conflictos recientes entre la Generalitat y las instituciones centrales del Estado, debe mencionarse ahora la Sentencia 74/2016, de 14 de abril (BOE, núm. 122, de 20 de mayo de 2016). En este caso, el Tribunal Constitucional resuelve el recurso de inconstitucionalidad interpuesto por el Presidente del Gobierno en relación con diversos preceptos de la Ley del Parlamento de Cataluña 12/2014, de 10 de octubre, del impuesto sobre la emisión de óxidos de nitrógeno a la atmósfera producida por la aviación comercial, del impuesto sobre la emisión de gases y partículas a la atmósfera producida por la industria y del impuesto sobre la producción de energía eléctrica de origen nuclear. El contencioso se centra en este último impuesto. La resolución, como va a verse, recae en términos análogos a la Sentencia anterior.

Así, de acuerdo con el Abogado del Estado, el impuesto catalán sobre la producción de energía eléctrica de origen nuclear, regulado en los preceptos impugnados de la mencionada Ley, habría vulnerado el art. 6.2 de la Ley Orgánica 8/1980, de 22 de septiembre, de financiación de las Comunidades Autónomas (LOFCA), porque su hecho imponible y demás elementos son coincidentes con los del impuesto estatal sobre la producción de combustible nuclear gastado y residuos radiactivos resultantes de la generación de energía nucleoeléctrica, regulado en la Ley 15/2012, de 27 de diciembre, de medidas fiscales para la sostenibilidad energética.

Por su parte, la representación procesal de la Generalitat de Catalunya consideró que el hecho imponible del impuesto controvertido concurre en la fase inicial del ciclo de producción y lo constituye el combustible nuclear que se introduce en el reactor, por el riesgo para el medio ambiente y los eventuales daños que dicha introducción y la 
subsiguiente reacción en cadena que genera puede producir en el referido medio ambiente, desde su introducción hasta su extracción. Con ello, diferiría del impuesto estatal, que se referiría al final de dicho proceso. En este sentido, el Letrado del Parlament de Catalunya alega que la mera utilización de combustible no equivale a producir combustible gastado, lo que incidiría en la diferenciación del hecho imponible, a lo que se añade el carácter extrafiscal del tributo previsto en la Ley controvertida, que se orientaría a la protección del medio ambiente.

Todo ello sitúa el contencioso en la determinación de si la Ley catalana infringe el art. 6.2 LOFCA, que establece que "[1]os tributos que establezcan las Comunidades Autónomas no podrán recaer sobre hechos imponibles gravados por el Estado". El Tribunal Constitucional concluye, de acuerdo con lo planteado por el Abogado del Estado, que

La diferencia estriba así entre el combustible «utilizado» y el «gastado», que no basta para sustentar la disimilitud de hechos imponibles, pues la «utilización» del combustible a que hace referencia el impuesto autonómico, dentro del proceso de producción de energía eléctrica de origen nuclear, no implica otra cosa que «producción» de combustible gastado, habida cuenta la inseparabilidad, en el proceso, de la utilización de combustible nuclear, por un lado, de la producción, por su utilización, de combustible nuclear «gastado», por otro. En suma, la utilización de combustible nuclear en el proceso de producción de energía eléctrica produce, inevitablemente, combustible nuclear gastado, pues éste no es sino el resultado del combustible nuclear utilizado. La conclusión es que en ambos tributos el hecho imponible consiste en la utilización de la energía nuclear para generar energía eléctrica. El hecho de que el autonómico se refiera al gasto o utilización de combustible nuclear para la producción, mientras que el estatal mencione la producción del combustible, no impide la conclusión de coincidencia, ya que, a la luz del proceso de producción que se expone en los propios escritos de las partes, parece claro que en ambos casos es preciso que el combustible nuclear sea gastado. En suma, lo que se sujeta a gravamen, en ambos tributos, es la utilización de combustible [FJ 4]

A partir de aquí, el Tribunal considera que

En este caso, en los términos examinados, la coincidencia entre los elementos esenciales permite concluir no sólo que se grava la misma actividad, sino que se hace también desde la misma perspectiva, sin que obste a la anterior conclusión la parcial 
afectación de su recaudación a la necesidad de financiar actuaciones de protección civil que, en todo caso, sería esencialmente coincidente en ambos tributos. No se trata ahora, como se afirma en el escrito de la representación procesal de la Generalitat de Cataluña, de un supuesto similar al decidido en la STC 60/2013, FJ 4, en el que se descartó la inconstitucionalidad del impuesto sobre determinadas actividades que inciden en el medio ambiente, en su modalidad de gravamen sobre las «actividades cuyas instalaciones emiten a la atmósfera dióxido de azufre, dióxido de nitrógeno o cualquier otro compuesto oxigenado del azufre o del nitrógeno» previsto en el art. 2.1 a) de la Ley de las Cortes de Castilla-La Mancha 16/2005. Allí establecimos, efectivamente, que cabe gravar la misma actividad desde dos perspectivas diferentes, concluyendo que no había coincidencia entre el tributo autonómico y el impuesto especial sobre la electricidad, regulado por la Ley 38/1992 de impuestos especiales.

La finalidad extrafiscal en relación con la protección del medio ambiente no es considerada seriamente por el Tribunal, lo que conlleva la crítica formulada en el voto particular suscrito por el Magistrado Juan Antonio Xiol Ríos. Particularmente, merecen retenerse las siguientes palabras:

Ya expuse en el Voto particular formulado a la STC 53/2016, de 17 de marzo, mi preocupación por la trivialización en que, a mi juicio, incurre la reciente jurisprudencia constitucional del derecho al medio ambiente consagrado en el art. 45 CE. Nuevamente debo insistir en esa inquietud. El art. $45 \mathrm{CE}$ impone al Estado que en la protección al medio ambiente se acuda al instrumento más radical con el que cuenta, como es su poder sancionador, apelando incluso a las sanciones penales (art. 45.3 CE). En coherencia con ello, no puedo compartir una lectura de la Constitución que no asuma la posibilidad de que el poder tributario, incluido el autonómico, intervenga como un instrumento más de protección medioambiental.

La sensibilidad mostrada por la jurisprudencia constitucional hacia la utilización del instrumento tributario en el cumplimiento de esa finalidad de protección medioambiental ha sido escasa y se ha vinculado exclusivamente con la acreditación de un daño real medioambiental y no de un riesgo potencial. El análisis de los diferentes pronunciamientos del Tribunal cuando se han planteado cuestiones relativas a impuestos autonómicos con finalidades extrafiscales medioambientales evidencia, a mi juicio, esa falta de sensibilidad, pero no la tan absoluta desatención que se ha puesto de manifiesto en este ocasión en la opinión mayoritaria en la que se sustenta la Sentencia. 
A partir de aquí, el Magistrado disidente considera que la finalidad extrafiscal está conveniente acreditada y permite considerar constitucional el impuesto controvertido. Así, señala que

La afirmación de los fines medioambientales del impuesto impugnado podría aparecer desacreditada, en los términos en los que ya se afirmó en las ya citadas SSTC 196/2012, FJ 3; y 60/2013, FJ 5, en relación con los impuestos a la producción termonuclear de electricidad establecidos en Castilla-La Mancha, y que parece es el criterio latente en la opinión mayoritaria en la que se sustenta la Sentencia, en que la selección del hecho imponible recae en «la utilización de combustible nuclear para la producción de energía eléctrica» (art. 23) y la base imponible queda constituida «por el peso de combustible nuclear utilizado en el período impositivo, expresado en toneladas». A la identidad de esos dos elementos se le da una predominante relevancia por la opinión mayoritaria en la que se sustenta la sentencia en el análisis comparativo que efectúa con el impuesto estatal, en tanto que su hecho imponible se configura con «la producción de combustible nuclear gastado resultante de cada reactor nuclear» (art. 15.1 de la Ley 15/2012) y su base imponible con «los kilogramos de metal pesado contenidos en el combustible nuclear gastado» (art. 17.1).

No me parece necesario, porque considero que no es elemento esencial del juicio de constitucionalidad, profundizar demasiado en que, desde luego, no concurre la identidad de hechos y bases imponibles. No pude decirse que sea lo mismo la utilización de combustible nuclear - hecho impositivo del tributo autonómico-que la producción de combustible nuclear gastado - hecho impositivo del tributo estatal- Ciertamente, ambos hechos son producto de la común actividad productiva - materia imponible - constituida por la generación de electricidad de origen nuclear, pero en sí mismos son, estrictamente hablando, actos distintos, hasta tal punto que, mientras para el tributo estatal la reutilización de combustible nuclear gastado extraído del reactor que fuera reintroducido con posterioridad en el reactor no daría lugar a un nuevo hecho imponible cuando fuera ulteriormente extraído (art. 15.2 de la Ley 15/2012), esa circunstancia sería irrelevante para el tributo autonómico, que seguiría considerándolo un hecho imponible autónomo. Igualmente, no puede decirse que la base imponible sea la misma, ya que mientras la estatal recae sobre la cantidad de material pesado presente en el combustible gastado - se toma como referencia el resultado final en que queda el combustible nuclear tras la actividad de fisión-, la autonómica lo hace sobre la cantidad de combustible nuclear efectivamente utilizado —se toma como referencia el 
combustible nuclear antes de la actividad de fisión-, y es evidente que la composición química del combustible queda alterada, precisamente, por la actividad de fisión propiciadora de la generación eléctrica.

Sin perjuicio de ello, insisto en que la concreta selección del hecho y de la base imponibles en el impuesto autonómico no puede tener esa pretendida eficacia excluyente de la finalidad extrafiscal medioambiental. En primer lugar, como ya se hiciera expreso en el Voto particular antes mencionado formulado a la STC 179/2006, porque, acreditada la finalidad extrafiscal del tributo, una eventual defectuosa selección del hecho imponible «no puede erigirse en canon de constitucionalidad por la elemental razón de que a este Tribunal no le corresponde emitir juicios de técnica legislativa (por todas, STC 37/2002, de 14 de febrero, FJ 6)». En segundo lugar, porque estimo que es absolutamente convincente y que forma parte de la lógica normativa la justificación que se da en la exposición de motivos de la normativa impugnada para avalar esa selección, cuando se afirma que en el caso de la producción eléctrica de origen nuclear, al no existir un riesgo medioambiental directamente vinculado a la producción, sino a eventuales incidencias en dicho proceso, el hecho imponible se configura por la propia utilización del combustible nuclear, frente a lo que se hace con el impuesto sobre la emisión de gases y partículas a la atmósfera producida por la industria, incluyendo la producción de generación eléctrica que no sea de origen nuclear. En efecto, creo que a estas alturas, conocidos determinados incidentes nucleares como los sucedidos en las centrales nucleares de Chernóbil y de Fukushima, no puede dudarse de los riesgos inherentes a este tipo de actividad tanto por su potencial incidencia sobre el medio ambiente como en las actuaciones de planificación en materia de protección civil. De ese modo, no puede entenderse como arbitraria o ilógico el seleccionar como hecho y bases imponibles un concreto acto que está en inmediata conexión con la finalidad extrafiscal perseguida. A esa misma conclusión se llegó, por ejemplo, en la STC 168/2004, cuando, al enjuiciarse la constitucionalidad del gravamen de protección civil a la producción de energía eléctrica previsto en la Ley 4/1997, de 20 de mayo, de protección civil de Cataluña, se argumentó que, si bien era un gravamen sobre los elementos patrimoniales afectos a actividades de las que pueda derivar la activación de planes de protección civil radicados en el territorio de la Comunidad Autónoma, «claramente se deduce que el objeto del gravamen no son dichos elementos patrimoniales, sino el riesgo potencial de las actividades e instalaciones allí mencionadas» (FJ 10) [las cursivas son mías]. 
En definitiva, el voto particular pone de manifiesto la vinculación entre regresión ambiental e involución autonómica, a la que ya me he referido al comenzar esta crónica. Asimismo, permite atisbar, en la evolución de la jurisprudencia del Tribunal en los últimos veinte años, ambos fenómenos, de modo que el Juez de la Constitución habría tendido a banalizar la autonomía, al mismo tiempo que a desligarse, cada vez más intensamente, de las tendencias jurisprudenciales comparadas en relación con el rol activo de la jurisdicción en la protección del medio ambiente.

\section{Unidad de mercado y protección del medio ambiente en el ámbito de los equipamientos comerciales}

La Sentencia 157/2016, de 22 de septiembre (BOE, núm. 263, de 31 de octubre de 2016), resuelve el recurso de inconstitucionalidad promovido por el Presidente del Gobierno en relación con el artículo único del Decreto-ley de la Generalitat de Cataluña 7/2014, de 23 de diciembre, por el que se deroga la letra b) del apartado 3 y el segundo párrafo del apartado 4 del artículo del Decreto-ley 1/2009, de 22 de diciembre, de ordenación de los equipamientos comerciales. En este caso, se puede ver aún con mayor claridad el conflicto confluyente entre autonomía y centralización, por una parte, y entre protección del medio ambiente y estímulo de la actividad económica, lo que pone de manifiesto, a mi juicio, un debate de fondo que transciende el contencioso en el que se hallan embarcados las autoridades catalanas y las instituciones centrales del Estado, aunque puede encontrar en ese desencuentro una expresión particularmente significativa.

El Abogado del Estado considera el Decreto-ley controvertido, al derogar el art. 9, apartado 3 b) y el segundo párrafo del art. 9.4 del Decreto-ley 1/2009, de 22 de diciembre, podría suponer la imposibilidad, sin excepción, de implantación de establecimientos comerciales fuera de la trama urbana consolidada. Esta limitación, sería, en su opinión, contraria al Derecho europeo por vulnerar la libertad de establecimiento del art. 49 TFUE. Alega en apoyo de esta consideración que la STJUE, en el asunto C-400/08, lo estimó así respecto de la regulación que establecía el art. 4.1 de la Ley catalana 18/2005, de 27 de diciembre, de equipamientos comerciales, que contenía una regulación similar. A partir de aquí, se fundamenta la incompatibilidad con la Constitución de la norma catalana a partir de su contradicción con la legislación básica del Estado dictada al amparo del art. 149.1.13, esto es, la planificación general de la actividad económica. Por lo demás, se 
excluye también la existencia del presupuesto habilitante para la elaboración de un decreto-ley.

A juicio de la representación procesal del Gobierno de la Generalitat, en cambio, la norma controvertida no infringiría la regulación básica del Estado, pues, aunque conlleva una medida restrictiva de la libertad de establecimiento, ésta cumpliría con todas las exigencias establecidas en ella, en la medida que habilitan las restricciones fundadas en razones imperiosas de interés público urbanístico, medioambiental y defensa de los consumidores. Por otra parte, según el Gobierno de la Generalitat, la medida adoptada, por lo demás, sería proporcionada, no discriminatoria y no encubriría requisitos de índole económica. En este sentido, el conflicto queda delimitado, fundamentalmente, en relación con la cuestión de si la norma autonómica constituye una restricción excepcional admitida por la legislación básica del Estado o no lo es. En términos similares se expresa la Letrada del Parlament de Catalunya. En cualquier caso, la protección del medio ambiente no sería aquí un título competencial, sino una justificación para que la competencia autonómica sectorial (comercio interior) pueda introducir una excepción admisible al régimen general de la legislación básica del Estado dictada en el marco del art. 149.1.13 CE.

El conflicto al entorno del mencionado Decreto-Ley se centra en la cuestión sustantiva, ya que el Tribunal Constitucional admite que se ha justificado suficientemente en el íter normativo la existencia de la extraordinaria y urgente necesidad a la hora de dictar la norma (FJ 6). Con ello, como he señalado, el núcleo del contencioso se condensa en el conflicto entre una interpretación de la legislación básica estatal que pretende garantizar la libertad de establecimiento, y una normativa autonómica que pretende limitarla en base a la protección de otros bienes jurídicos, entre los cuales la protección del medio ambiente. A partir de aquí, se trata de ver si la normativa básica estatal, que prevé medidas excepcionales de carácter limitativo basadas en razones de interés general, permite la medida adoptada por la Comunidad Autónoma.

De acuerdo con el Tribunal Constitucional, no sería el caso ya que,

[p]ara entender que concurren las razones imperiosas de interés general exigidas por la normativa básica estatal para que pueda establecerse una restricción al principio de libertad de establecimiento no basta con que el legislador apele a tales razones, sino que es preciso que se aporten en el presente proceso los datos precisos en las que se justifica la adopción de la medida limitativa de acuerdo con tales razones, pues solo en tales casos podrá apreciarse, cuando surge una controversia sobre la 
constitucionalidad de la medida, que la limitación establecido tiene como finalidad la consecución de fines de interés general que la legitiman.

En el presente caso, las razones medioambientales y urbanísticas que, según se expone en el preámbulo del Decreto-ley impugnado, fundamentan la derogación de los preceptos que excepcionalmente permitían la implantación de determinados centros comerciales fuera de la trama urbana consolidada han de considerase razones imperiosas de interés general y son razones, que, por su naturaleza y en un plano formal, se ajustan a las previstas en la legislación básica estatal y a las reconocidas por la jurisprudencia del Tribunal de Justicia de la Unión Europea. Como ha señalado la STJUE de 24 de marzo de 2011, (C-400/08), «[e]ntre esas razones imperiosas reconocidas por el Tribunal de Justicia figuran la protección del medio ambiente (véase, en particular, la Sentencia de 11 de marzo de 2010, Attanasio Group, C384/08, Rec. p. I-0000, apartado 50 y jurisprudencia citada), la ordenación del territorio (véase, por analogía, la sentencia de 1 de octubre de 2009, Woningstichting Sint Servatius, C-567/07, Rec. p. I-9021, apartado 29 y jurisprudencia citada) y la protección de los consumidores (véase, en particular, la Sentencia de 13 de septiembre de 2007, Comisión/Italia, C-260/04, Rec. p. I-7083, apartado 27 y jurisprudencia citada)» (apartado 74). Por esta razón la citada STJUE de 24 de marzo de 2011 (C-400/08), consideró que «las restricciones relativas al emplazamiento y al tamaño de los grandes establecimientos comerciales parecen medios adecuados para alcanzar los objetivos de ordenación del territorio y de protección del medio ambiente invocados por el Reino de España» (apartado 80).

Ahora bien, como también declaró el Tribunal de Justicia de la Unión Europea en la Sentencia citada, para que las referidas limitaciones sean legítimas es necesario, además, aportar «datos suficientes para explicar por qué motivos las restricciones controvertidas son necesarias para alcanzar los objetivos perseguidos» (apartado 84). Y fue, precisamente, «la falta de explicaciones y ... la significativa repercusión de las limitaciones examinadas sobre la posibilidad de abrir grandes establecimientos comerciales en el territorio de la Comunidad Autónoma de Cataluña» lo que determinó que el Tribunal de Justicia no considerase justificadas las restricciones de la libertad de establecimiento que la normativa que estaba enjuiciando -normativa que, como se ha señalado, era similar a la que rige esta materia tras la derogación que efectúa el Decreto-ley impugnado- y declarase que las restricciones de la libertad de establecimiento que conllevaba no estuvieran justificada (apartado 85).

Esta falta de explicaciones y de datos suficientes concurre también el presente proceso constitucional. 
Las Comunidades Autónomas, al amparo de sus competencias en materia de urbanismo y medio ambiente, ejercitadas en virtud de su autonomía política, pueden adoptar las medidas que consideren más oportunas para propugnar un determinado modelo de ciudad o de urbanismo comercial. No obstante, tales medidas han de adoptarse teniendo en cuenta las exigencias que se derivan de la legislación básica estatal y deben tomar en consideración la especial exigencia de precisión de los datos justificativos, en correspondencia con el rigor con que en el ámbito de la Unión debe ser tratado por los tribunales el principio de libertad de establecimiento. Sin embargo, las razones invocadas por el Decreto-ley ahora impugnado, las cuales son adecuadas por su naturaleza para justificar limitaciones a la libertad de establecimiento, no pueden considerarse suficientes, en el marco de la presente controversia constitucional, para fundamentar una medida como la adoptada en el presente caso que,, conlleva la prohibición prácticamente absoluta de la implantación de determinados centros comerciales fuera de la trama urbana consolidada, si no se aportan al proceso los «datos precisos» para entender necesaria la restricción a la libertad de establecimiento que la misma conlleva.

Las consideraciones sobre los daños al entorno urbano y al medio ambiente que se efectúan en el preámbulo del Decreto-ley, al igual que las realizadas en la memoria que se presentó junto con el anteproyecto de esta norma, se formulan de modo abstracto, sin partir de datos concretos que pongan de manifiesto la necesidad de la medida para promover el objetivo pretendido, pues el único dato que se aporta es el que indica que la mayoría de las licencias para establecer este tipo de centros se han otorgado al amparo de las excepciones previstas en los preceptos que deroga el Decreto-ley. Este dato, con ser relevante, solo justifica que al amparo de estos preceptos se ha otorgado la mayoría de las autorizaciones solicitadas para la implantación de este tipo centros, pero en modo alguno evidencia que la prohibición prácticamente absoluta de la implantación de determinados centros comerciales fuera de la trama urbana consolidada sea una medida necesaria, por la inexistencia de alternativas menos restrictivas, para promover los legítimos objetivos pretendidos.

Por todo ello ha de concluirse que en el presente caso no se ha fundamentado debidamente que concurran las imperiosas razones de interés general relacionadas con el entorno urbano o el medio ambiente, que exige la legislación básica estatal para poder adoptar una medida restrictiva de la libertad de establecimiento como la establecida en el Decreto-ley impugnado. La Comunidad Autónoma no ha justificado durante el proceso la necesidad de las restricciones controvertidas para 
alcanzar los legítimos objetivos perseguidos, lo que determina el incumplimiento de la legislación básica estatal.

El incumplimiento de estas exigencia determina que no sea preciso valorar si son materialmente básicas las nuevas exigencias introducidas por Ley 18/2014 en la redacción dada al art. 6 LOCM, ni si el legislador autonómico las ha desatendido.

Los razonamientos expuestos conducen a afirmar que el Decreto-ley de la Generalitat de Cataluña 7/2014, de 23 de diciembre infringe la normativa básica estatal integrada por los arts. 6 de la Ley de ordenación del comercio minorista y 11 de la Ley 17/2009, y, en consecuencia, vulnera de un modo mediato o indirecto el reparto constitucional de competencias que delimita el art. 149.1.13 CE en relación con el art. 121.1 d) EAC, lo que determina su inconstitucionalidad [FJ 9].

En definitiva, a juicio del Tribunal, la Generalitat no ha acreditado suficientemente la existencia de razones justificativas. El rigor del Alto Tribunal en este caso contrasta con la generosidad con que acoge las justificaciones abstractas y genéricas para considerar que la legislación estatal no se enmarca en el ámbito de la protección del medio ambiente en la Sentencia 53/2016, de 17 de marzo, comentada unas páginas más arriba. De hecho, en el voto particular formulado por los magistrados Adela Asua Batarrita y Fernando Valdés Dal-Ré se defiende justamente que la Generalitat

$[\mathrm{H}]$ a justificado con amplio detalle las razones imperiosas de interés general, basadas en la protección del medio ambiente y el entorno urbano, que le han llevado a derogar los preceptos que excepcionalmente permitían con anterioridad la implantación de determinados centros comerciales. La memoria que acompaña al anteproyecto de decreto-ley dedica un amplio espacio a exponer esas razones imperiosas de interés general: a lo largo de cinco páginas se recuerdan las exigencias que a este respecto señaló la STC 193/2013, se señalan los «fundamentos territoriales y de protección medioambiental para justificar la eliminación la excepcionalidad» y se glosan los «efectos perversos de la aplicación de la excepcionalidad». También el preámbulo del Decreto-ley 7/2014 contiene una amplia justificación, que sintetiza la aportada por la citada memoria. Por tanto, la afirmación que se contiene en la Sentencia sobre la «falta de explicaciones» resulta, a nuestro juicio, gratuita.

Parece que nos encontramos, pues, ante el mismo sesgo al que hemos hecho referencia en las sentencias comentadas anteriormente, por lo que no es necesaria una ulterior reflexión, más allá de señalar la repetición de un patrón que va haciéndose, 
lamentablemente, demasiado habitual y que nos permite hacer la consideración inicial que abre esta crónica.

\section{La gestión de permisos y concesiones en relación con el almacenamiento geológico de dióxido de carbono}

Aparte de los numerosos contenciosos que en el período analizado afectan a las relaciones entre la Generalitat de Catalunya y las instituciones centrales del Estado, cabe mencionar en esta crónica la Sentencia 165/2016, de 6 de octubre (BOE núm. 276, de 15 de noviembre de 2016), que resuelve el recurso de inconstitucionalidad interpuesto por el Gobierno de Aragón respecto de diversos preceptos de la Ley 40/2010, de 29 de diciembre, de almacenamiento geológico de dióxido de carbono. Nuevamente, el aspecto conflictivo de la cuestión se centra en la atribución de competencias ejecutivas a la Administración central del Estado. En este sentido, el Gobierno de Aragón considera que discute que sea constitucional la atribución a la Administración General del Estado de la gestión de permisos y concesiones en este ámbito.

En este contencioso, el Tribunal Constitucional opta, en primer lugar, por considerar que el título competencial de aplicación al caso es el relativo al régimen minero (art. 149.1.25), para concluir que el Estado, estableciendo las bases en tal ámbito puede optar por una ejecución centralizada. Así, el Alto Tribunal afirma

Así, como hemos visto en fundamentos jurídicos anteriores, la Ley 40/2010 establece un marco regulador específico para una tecnología novedosa, que se encuentra en proceso de experimentación y desarrollo y que ofrece indudables ventajas en la lucha contra el cambio climático y, al mismo tiempo, indudables riesgos para la salud y el medio natural. En su afán por impulsar el desarrollo de esta nueva tecnología, la Directiva 2009/31 de la Unión Europea ha introducido un conjunto de reglas, de entre las cuales destaca aquella que considera que los Estados miembros tienen competencia para decidir las zonas en las que podrán situarse los emplazamientos de almacenamiento; potestad que «incluye el derecho de los Estados miembros a no permitir almacenamiento alguno en partes de su territorio o en la totalidad del mismo» (art. 4.1 de la Directiva 2009/31). A diferencia de otros Estados miembros, el Reino de España ha optado, dentro del margen de libre configuración legislativa que le corresponde, por no establecer prohibiciones de carácter general o zonal en las disposiciones legales, sino de apreciar la posibilidad 
de autorizar o denegar el uso del territorio español atendiendo a las circunstancias de cada caso concreto y en función de los estudios que toda empresa interesada deba llevar a cabo (arts. 10.1 y 11.5 de la Ley 40/2010).

Igualmente, señala que uno de los ejes centrales del régimen establecido por la Directiva 2009/31 y plasmado en nuestro Derecho por la Ley 40/2010 consiste en prever que, cuando la concesión del dominio minero se extinga, los Estados miembros deben asumir directamente la responsabilidad derivada del almacenamiento del dióxido de carbono de manera indefinida. Esa transferencia de responsabilidad, regida por el art. 24 de la Ley 40/2010 (como vimos en el fundamento jurídico 6), no impugnado por la demanda de inconstitucionalidad, hace recaer la responsabilidad por cualquier fuga o daño que pudiera producirse en los lugares de almacenamiento del dióxido de carbono, una vez extinguida la concesión demanial y vencido el plazo de transición posterior, y por un plazo indefinido, directamente sobre el Estado.

La normativa básica estatal ha optado por un modelo de gestión centralizada de las concesiones de almacenamiento y no por un modelo de gestión autonómica. Este modelo se justifica en el hecho de que las concesiones de almacenamiento, que confieren a sus titulares el derecho en exclusiva a almacenar $\mathrm{CO} 2$ en un concreto lugar, no constituyen sino la última fase de un proceso más complejo que se pretende promover a través de la implantación de la nueva tecnología regulada, pues, si bien es cierto que la ley impugnada se limita a regular la actividad de almacenamiento geológico de dióxido de carbono y sólo contiene previsiones puntuales en relación con la captura y el transporte de aquel, también lo es que, para tener una visión completa de la nueva tecnología que se pretende desarrollar, es indispensable tomar en consideración la interconexión que se debe producir entre los lugares de almacenamiento, las redes de transporte y las instalaciones de captura. Redes de transporte e instalaciones de captura que pueden tener una clara dimensión supraterritorial, e incluso supranacional, pues recordemos que la Directiva 2009/31 de la Unión Europea reconoce a los Estados miembros el derecho a no permitir almacenamiento alguno en partes de su territorio o en la totalidad del mismo (art. 4.1 de la Directiva 2009/31), no quedando, sin embargo, por ello excluidos tales Estados de la posibilidad de utilizar los lugares de almacenamiento de otro Estado que sí los permita.

La evidente dimensión supraterritorial del fenómeno regulado se refleja, igualmente, en el Preámbulo de la norma impugnada en el que se destaca cómo el establecimiento de grandes instalaciones de combustión - grandes centrales térmicas- de 
competencia estatal vendrá íntimamente asociado a la obtención de concesiones de almacenamiento.

En la línea referida, este Tribunal, en relación con la ordenación del sector de la energía nuclear y radioactiva, tuvo ya la oportunidad de afirmar la constitucionalidad de aquella normativa básica estatal que había optado por un sistema abierto a todo el territorio nacional y no por un modelo de gestión autonómica de los residuos radioactivos, pues en aquella ocasión consideramos que «corresponde al legislador básico, en razón a las características estructurales de que se pretenda dotar al sector de la energía nuclear, decidir si los residuos generados en una Comunidad Autónoma han de ser necesariamente almacenados en la misma Comunidad, o si, por el contrario, resulta más adecuado distribuir estratégicamente los centros de producción y los almacenes de residuos de esta modalidad de energía, teniendo como referencia el conjunto del territorio nacional, según las pautas que se estimen convenientes» [STC 14/2004, de 13 de febrero, FJ 13] [FJ 10].

Sin embargo, como sucede con el caso de la protección del medio ambiente, la Constitución asigna a las instituciones centrales del Estado "las bases del régimen minero y energético", de lo que se deriva que la ejecución es, por principio, autonómica, en el caso de que exista una asunción estatutaria en este ámbito. Por ello, la argumentación de la Sentencia es discutible, en la medida que una cosa es que el Estado pueda dictar las bases en esta materia y otra cosa es que pueda atribuirse la ejecución al dictarlas. En este sentido razona el voto particular subscrito por la magistrada Adela Asua Batarrita, al que se adhiere el magistrado Juan Antonio Xiol Ríos. Así, se dice

La distribución de competencias en la materia «régimen minero» es clara. Al Estado le corresponde la legislación básica (art. 149.1.25 CE) y a las Comunidades Autónomas su desarrollo legislativo y la ejecución de la legislación básica y de la legislación autonómica que la desarrolle. Dado que la Comunidad Autónoma de Aragón no impugna la regulación sustantiva contenida en la Ley 40/2010, sino solo las facultades que la Ley impugnada reserva a la Administración General del Estado para su ejecución, bastaría haber comprobado el carácter ejecutivo de las facultades controvertidas para concluir que su titularidad debe corresponder a las Comunidades Autónomas. Un marco de distribución competencial que, como recuerda la entidad recurrente, fue aplicado sin problemas hasta la entrada en vigor de la Ley 40/2010.

En lugar de un enfoque plenamente ajustado al orden constitucional de distribución de competencias (que se despacha con displicencia como aplicación «literal» de la «regla general»), la Sentencia avala, en los fundamentos jurídicos 10 a 12, un reparto 
competencial distinto diseñado por el legislador básico, que desapodera casi completamente a las Comunidades Autónomas de sus facultades ejecutivas en este ámbito.

De acuerdo con nuestra doctrina, debe existir una justificación convincente de la asunción estatal de competencias ejecutivas en una materia que, en principio, corresponde a las Comunidades Autónomas (por todas, STC 223/2012, de 29 de noviembre, FJ 7). Cuando, además, el legislador básico pretende alterar casi por completo la regla ordinaria de la competencia ejecutiva autonómica para una materia o una legislación determinada, que se ha aplicado pacíficamente con anterioridad, considero que la justificación debe ser especialmente poderosa [la cursiva es mía].

Seguidamente, se justifica por qué tal justificación no se da en el caso concreto, para concluir con una reflexión general que manifiesta las mismas prevenciones que he manifestado a lo largo de esta crónica. Dice el mencionado voto particular in fine:

En el Voto particular formulado a la STC 107/2014, de 26 de junio, manifesté mi discrepancia con la generalización acrítica e incondicionada de la línea jurisprudencial que admite excepcionalmente la adopción de actos de ejecución como parte de lo básico, fuera del ámbito y de las razones por las cuales se desarrolló originalmente. Tal como he indicado más arriba, se trata de una línea jurisprudencial originalmente desarrollada para justificar el ejercicio de facultades ejecutivas concretas por organismos muy específicos como el Banco de España, esto es, en el ámbito de las «bases de la ordenación de crédito, banca y seguros» (art. 149.1.11 CE). Posteriormente se reformuló en la STC 31/2010, de 28 de junio, FJ 60, en unos términos tan generales e incondicionales que han provocado incorrectamente, a mi juicio, el entendimiento de que la competencia estatal sobre las bases incluye con toda naturalidad la posibilidad de dictar actos de ejecución en cualquier materia. Esta es la formulación extensiva de una línea jurisprudencial, inicialmente excepcional y acotada a ciertas materias, a la que se acoge la presente Sentencia. Como afirmé en el Voto particular antes mencionado, «esa doctrina lleva camino de dejar de ser excepcional dando lugar a una alteración de la distribución competencial». Como se comprueba con el análisis de la presente y de otras Sentencias recientes, ese particular entendimiento conduce a una importante alteración de las reglas de distribución competencial que derivan del bloque de constitucionalidad y produce, en consecuencia, un preocupante efecto corrosivo sobre las competencias de ejecución de las Comunidades Autónomas, cuyo ámbito competencial se va reduciendo progresivamente. En el presente supuesto, la aplicación de la citada doctrina por este Tribunal no sirve para justificar que los 
órganos centrales del Estado adopten concretos actos singulares de ejecución en situaciones precisas, sino que llega hasta el extremo de producir una drástica ablación de casi la totalidad de las facultades ejecutivas de las Comunidades Autónomas relativas al almacenamiento geológico de dióxido de carbono [la cursiva es mía].

Hago mío el razonamiento de la magistrada Asua Batarrita, que, a mi juicio, pone de manifiesto uno de los problemas fundamentales en relación con la articulación jurisprudencial del sistema constitucional de distribución de competencias en tiempos recientes y muestra con meridiana claridad la involución autonómica emprendida por el Tribunal Constitucional en la última década, una involución cuyo apoyo en el texto de la Constitución es sencillamente inexistente. El deterioro consiguiente del Estado de las Autonomías es evidente, así como la progresiva articulación del Tribunal Constitucional como una institución claramente sesgada en la defensa de los intereses del Estado central. Los efectos de tal orientación en la legitimidad del Tribunal empiezan a ser francamente peligrosos.

\section{Auditoría ambiental y distribución de competencias}

En medio de tantas resoluciones que aúnan recentralización y postergación de la protección del medio ambiente en relación con el desarrollo económico, merece destacarse la Sentencia 141/2016, de 21 de julio (BOE, núm. 196, de 15 de agosto de 2016), en que el Tribunal adopta una perspectiva más respetuosa con las competencias autonómicas, aunque los efectos positivos desde el punto de vista de la protección del bien jurídico sean menos recognoscibles. En este caso, se resolvía el conflicto positivo de competencia planteado por el Gobierno de la Generalitat de Catalunya respecto de diversos preceptos del Real Decreto 239/2013, de 5 de abril, por el que se establecen las normas para la aplicación del Reglamento (CE) núm. 1221/2009, del Parlamento Europeo y del Consejo, de 25 de noviembre de 2009, relativo a la participación voluntaria de organizaciones en un sistema comunitario de gestión y auditoría medioambientales (EMAS) y por el que se derogan el Reglamento (CE) núm. 761/2001 y las Decisiones 2001/681/CE y 2006/193/CE, de la Comisión.

En concreto, el Gobierno catalán consideró que los arts. 9.1 y 2, 11.1 y 2, 12.1 y 4, 13.2, la disposición transitoria primera, y la disposición final tercera del Real Decreto 239/2013 
invadían su ámbito competencial. Esto sería así, a criterio del Gobierno de la Generalitat, por el hecho de que asignan funciones ejecutivas en relación con la protección del medio ambiente a las Administración central del Estado. Por su parte, el Abogado del Estado parte de la idea de que la misma norma de la Unión Europea traspuesta en el referido Real Decreto exige la existencia de una sola entidad de verificación por estado, lo que habilitaría la existencia de actos de ejecución en materia de protección del medio ambiente por parte del Estado, cosa que ha sido excepcionalmente admitida por la jurisprudencia constitucional. En definitiva, el conflicto se centra sobre la posibilidad de que, en el caso concreto, se de o no justificación suficiente para la existencia de actos de ejecución del Estado, incardinados, de manera excepcional, en su competencia relativa a la legislación básica en relación con la protección del medio ambiente.

Efectivamente, como señala el propio Tribunal Constitucional, "conforme al art. 11.1 del Real Decreto 239/2013 «deberán obtener acreditación de la Entidad Nacional de Acreditación, organismo nacional de acreditación designado por Real Decreto 1715/2010, de 17 de diciembre». La principal discrepancia entre las partes en torno a esta cuestión está directamente relacionada con el alcance de la nueva normativa de la Unión Europea y su adecuada aplicación en el ordenamiento interno conforme al sistema interno de distribución de competencias, tal como fue delimitado por la STC 33/2005" (FJ 4). En definitiva, se trata de ver si la modificación del Derecho de la Unión Europea aplicable al caso modifica la doctrina sobre la cuestión establecida por el Juez de la Constitucionalidad en su jurisprudencia previa.

Pues bien, el Tribunal Constitucional decide de acuerdo con su jurisprudencia previa y establece que

A este Tribunal no le corresponde establecer cuál sea la interpretación correcta del Reglamento (CE) núm. 1221/2009, sino resolver el conflicto de competencias que ha suscitado el Real Decreto 239/2013 entre el Gobierno de la Generalitat de Cataluña y el del Estado. Teniendo en cuenta la regulación del mencionado Reglamento europeo es claro que el Real Decreto controvertido no ha atendido a la obligación de «conciliar, en la mayor medida posible, el orden interno de distribución de poderes, por un lado, y el cumplimiento pleno y tempestivo de las obligaciones del Estado en el seno de la Unión, por otro»; por otra parte «el desarrollo normativo del Derecho de la Unión Europea en el ordenamiento interno debe realizarse desde el pleno respeto de la estructura territorial del Estado» (STC 20/2014, FJ 3, y las allí citadas). Resulta pues indiscutible que el Reglamento (CE) 
núm. 1221/2009 no obliga a que el poder central de cada Estado miembro designe una única autoridad de acreditación o autorización; habrá de ser el legislador quien, a la vista del Reglamento europeo, explore la forma de hacer compatible el cumplimiento de las exigencias que éste impone con el régimen de distribución competencial, teniendo en cuenta el principio constitucional de colaboración, implícito en el sistema de las autonomías (entre muchas, STC 152/1988, de 20 de julio, FJ 10). El correcto funcionamiento del sistema autonómico depende en buena medida de que el Estado y las Comunidades Autónomas desarrollen fórmulas racionales de cooperación, acuerdo o concertación (por todas, SSTC 247/2007, de 12 de diciembre, FJ 23, y 20/2016, de 4 de febrero, FJ 2).

Por consiguiente ha de concluirse que el art. 11.1 del Real Decreto 239/2013, al atribuir en exclusiva a la Entidad Nacional de Acreditación la acreditación de los verificadores medioambientales, invade las competencias ejecutivas de la Generalitat de Cataluña en materia de medio ambiente y vulnera por tanto el orden constitucional de distribución de competencias (arts. 149.1.23 CE y 144.1 EAC). La inconstitucionalidad del art. 11.1 comporta, por la misma razón, la de la regulación conexa: art. 11.2 (obligación de inscribir a los verificadores medioambientales en un registro estatal de industria); art. 12.1 y 4 (competencia de la Entidad Nacional de Acreditación para supervisar la actividad de los verificadores medioambientales) y disposición transitoria primera (que atribuye la competencia para la renovación de las acreditaciones de los verificadores medioambientales a la Entidad Nacional de Acreditación).

En conclusión, corresponde declarar la inconstitucionalidad y nulidad de los arts. 11, apartados 1 y 2, y 12, apartados 1 y 4, así como de la disposición transitoria primera, todos del Real Decreto 239/2013.

De este modo, el Tribunal resuelve, en este caso, a favor de la Comunidad Autónoma afectada, reposando en su propia doctrina anterior y, evitando la expansión de las competencias ambientales del Estado hasta la inclusión de actos de ejecución en el caso concreto. Esta Sentencia, como puede verse, más bien excepcional en la trayectoria reciente del Tribunal, señala un camino que podría ser inspirador, al contrario que las otras resoluciones comentadas. Lamentablemente, parece ser más bien una excepción en relación con la línea jurisprudencial dominante del Tribunal en tiempos recientes. 